\title{
ROBUST BIODEGRADABLE CHITOSAN FILM REINFORCED CELLULOSE ISOLATED FROM STRAW WASTE
}

\author{
M. Hasan ${ }^{\bowtie}$, F. Zarlaida, D. Susilawati, Zulfadli, M. Nasir and L. Hanum \\ Department of Chemistry Education, Universitas Syiah Kuala, Darussalam, 23111, \\ Banda Aceh, Indonesia \\ ${ }^{\circledR}$ Corresponding Author: muhammadhasan.kimia@unsyiah.ac.id
}

\begin{abstract}
Chitosan-based films have lower mechanical characteristics, thermal stability, and barrier properties as compared to synthetic polymers, limiting their applicability. The incorporation of cellulose is another interesting approach to enhance the thermomechanical and barrier properties of chitosan-based films. Biodegradable films made of chitosan $(\mathrm{CH})$ and cellulose $(\mathrm{CL})$ were created and described. Surface roughness, structure, mechanical properties such as tensile strength (TS) and elongation at break (EB), water uptake, and biodegradation tests of the CHCEL blend films are all presented.The addition of cellulose to the chitosan matrix improved mechanical strength despite reduced water absorption. After 15 days of burial in various cellulose contents, the film is fully biodegradable with no crumbs. Based on the findings of this study, CHCEL composite films prepared through this research have a high potential for implementation as sustainable food packaging films.
\end{abstract}

Keywords: Cellulose, Chitosan, Biodegradable Film, Food Packaging

RASĀYANJ. Chem., Vol. 14, No.3, 2021

\section{INTRODUCTION}

Researchers have recently expressed a strong interest in the development of biodegradable food packaging films made from natural polymeric materials, owing to the rising environmental pollution caused by the usage of plastics derived from petrochemical raw materials. ${ }^{1-3}$ Among natural polymeric materials, chitosan is regarded as a promising raw material for the production of biodegradable films. Chitosan is a cationic polysaccharide that contains a (1-4) -2-amino-deoxy d-glucopyranose unit. It has a strong film-forming capability, adequate mechanical strength, antibacterial activity, is non-toxic, biocompatible, renewable, and abundant in nature ${ }^{4}$. The presence of three distinct functional groups (primary $-\mathrm{OH}$, secondary $-\mathrm{OH}$, and $-\mathrm{NH}_{2}$ ) is contributed to the major property of chitosan. ${ }^{4}$

However, when compared to synthetic polymers, natural chitosan has poor mechanical property, thermal stability, and barrier abilities, restricting its applicability. The interaction will occur when chitosan is combined with other various structures and properties of biopolymers, which can synergistically improve these characteristics. Several studies have been performed on the consequences of chitosan blending with other polymers, including chitosan and yellow pumpkin starch ${ }^{5}$, chitosan and brown rice $\operatorname{starch}^{6}$, $\operatorname{chitosan}^{-}$ caseinate $^{7}$, and high methoxyl apple pectin-chitosan. ${ }^{8}$ The inclusion of cellulose is another intriguing method for enhancing the thermo-mechanical and barrier properties of chitosan-based films.

This paper describes the research of biodegradable films made by combining chitosan and cellulose fiber from waste straws. To the best of our knowledge, this is the first publication on films made from chitosan by incorporating cellulose from straw waste. The obtained films were examined using FTIR, AFM, tensile strength, water absorption, and biodegradation tests. The findings of this study could be beneficial in terms of obtaining novel formulations for manufacturing biodegradable edible films that can be used for sustainable film packaging.

\section{Material and Methods}

\section{EXPERIMENTAL}

Rice straw was collected in the Aceh Besar districts of Aceh Province, Indonesia. Chitosan powder (molecular weight $102 \mathrm{KDa}$; particle size 200-300 mesh; degree of deacetylation 96.24 percent) was purchased from Chimultiguna Co., Ltd. (Indramayu, Indonesia). Subur Jaya Kimia Co. Ltd. provided the 
RASĀYAN J. Chem.

Vol. 14 | No. 3 |2147-2153| July - September | 2021

castor oil (Bandung Indonesia). sodium hydroxide, sulfuric acid 98\%, vaseline, hydrochloric acid 36\%, and glacial acetic acid from Sigma-Aldrich (Darmstadt, Germany).

\section{Extraction of Cellulose}

Extraction of cellulose fiber (CEL) from rice straw is based on the earlier publication ${ }^{9-10}$, with small alterations. Rice straw was cleaned, dried in the sun, mashed, and sieved until it had a particle size of 50 mesh. The sample was then placed into a beaker containing $17.5 \%$ sodium hydroxide solution in a weight-to-solvent ratio of 1:10, and soaked for $2 \mathrm{~h}$. After successive washes with distilled water, the samples were hydrolyzed with $1 \mathrm{M} \mathrm{HCl}$ at a temperature of $80-85^{\circ} \mathrm{C}$ for $2 \mathrm{~h}$. The sample was repeatedly washed with distilled water.After adding a $2 \%$ sodium hydroxide solution to the sample, it is washed multiple times with distilled water until the $\mathrm{pH}$ of the fiber is neutral, then filtered and dried at room temperature.

\section{Film Preparation}

With minor modifications, blend films were cast using the solvent casting method ${ }^{11}$. Chitosan (CS) and cellulose fiber (CEL) were weighed at different weights (Table-1). 3\% (w/v) $\mathrm{CH}$ solution was made by dissolving a certain amount of $\mathrm{CH}$ in $1.5 \%$ acetic acid solution and stirring with a magnetic stirrer at $90^{\circ} \mathrm{C}$ for $30 \mathrm{~min}$. Slowly, a predetermined amount of CEL and $15 \%$ castor oil were added to the $\mathrm{CH}$ solution. ${ }^{11}$ For $20 \mathrm{~min}$, the mixture was agitated with a magnetic stirrer at $1300 \mathrm{rpm}$. The sample was then placed into an acrylic petri dish and dried in an oven at $45^{\circ} \mathrm{C}$ until all of the solvents had evaporated and a film had formed.The film was then maintained in a control room for $36 \mathrm{~h}$ at $25^{\circ} \mathrm{C}$ and $55 \% \pm 2 \% \mathrm{RH}$ before being analyzed. ${ }^{1}$

Table-1: Experimental design

\begin{tabular}{c|c|c|c}
\hline \multirow{2}{*}{ Film Samples } & \multicolumn{3}{|c}{ Material weight $(\mathrm{g})$} \\
\cline { 2 - 4 } & Cellulose & Chitosan & Castor Oil \\
\hline CHCEL0 & 0.00 & 3.40 & 0.600 \\
\hline CHCEL1 & 0.04 & 3.36 & 0.600 \\
\hline CHCEL3 & 0.12 & 3.28 & 0.600 \\
\hline CHCEL5 & 0.20 & 3.20 & 0.600 \\
\hline CHCEL7 & 0.28 & 3.12 & 0.600 \\
\hline
\end{tabular}

\section{Fourier Transform Infrared (FTIR) Spectroscopy}

IR spectra were used to determine the microstructure of a hybrid film. It was acquired with a Cary 630 FTIR spectrometer (Agilent Technologies, USA). With a resolution of $4 \mathrm{~cm}^{-1}$, the measurement was scanned in the wavenumber range of 600 to $4000 \mathrm{~cm}^{-1}$. The film was placed directly to the sample holder. $^{12}$

\section{Thickness and Water Uptake}

At three distinct sites, the thickness of the film was measured with a digital micrometer (Mitutoyo IP 65, Japan). The gravimetric approach was applied to quantify the water uptake of the film samples ${ }^{13}$. Before measurement, all films were cut into $2 \mathrm{~cm} \times 2 \mathrm{~cm}$ squares, dried, and stored at $25^{\circ} \mathrm{C}$ and $100 \% \mathrm{RH}$ for 36 $\mathrm{h}$, and the initial weight $\left(\mathrm{W}_{\mathrm{i}}\right)$ was recorded. The films were then immersed in distilled water for $10 \mathrm{sec}$ while being retrieved from the water and cleansed with a tissue to get the final weight, $\mathrm{W}_{\mathrm{f}}$. The procedure was repeated until a stable weight was achieved. The water uptake from the film sample was calculated using eq. $-1 .{ }^{14}$

water uptake $=\frac{W_{f}-W i}{W i} \quad 100 \%$,

The adsorption process in the films can be explained kinetically using the second Fick's law of diffusion (eq.-2). ${ }^{15}$ The initial kinetics of sorption are as follows:

$$
\frac{M_{t}}{M_{\infty}}=\frac{4}{L} \sqrt{\frac{D x t}{\pi}}(2)
$$


where $M_{t}$ and $M_{\infty}$ are mass of water (g) absorbed at time t, the mass of water absorbed at thermodynamic equilibrium respectively, and $\mathrm{L}$ is the thickness of the film. The diffusion coefficient, $\mathrm{D}$, is expressed as a slope obtained by fitting a line of $M_{t} / M_{\infty}$ versus $\sqrt{t}$ of the straight-line partof $\mathrm{R}^{2}$ over $99 \% .{ }^{8}$

\section{Atomic Force Microscopy (AFM)}

AFM (Veeco Instruments, Santa Barbara, CA, USA) with a type E piezoelectric scanner was used to do topographic analysis on the film. Surface roughness, as indicated by $\mathrm{Ra}$ and $\mathrm{Rq}$ values, is the parameter observed. Ra denotes the mean square root, whereas $\mathrm{Rq}$ is the arithmetic mean of the absolute values of surface height deviation measured from the average plane. A $1.5 \mathrm{~cm} \times 1.5 \mathrm{~cm}$ film was prepared and examined under the following conditions: a force constant of $42 \mathrm{~N} \mathrm{m1}$, a resonance frequency of 320 $\mathrm{kHz}$, and a doped antimony silicon probe with a nominal tip radius of $8 \mathrm{~nm} .{ }^{11}$

\section{Mechanical Properties}

Mechanical parameters of the films, such as tensile strength (TS) and elongation at break (EB), were evaluated with an IK Tester MCT-2150 apparatus (A \& D, Co., Ltd., Tokyo, Japan). The measurement was carried out following the ASTM 0638 method. All samples were $4.0 \mathrm{~cm} \times 1.0 \mathrm{~cm}$ in size for the measurements. A $5 \mathrm{kN}$ load and a speed of $0.030 \mathrm{~m} / \mathrm{min}$ were employed. Before testing, the specimens were kept at room temperature with a relative humidity of $52 \%$ for $24 \mathrm{~h}$.

\section{Biodegradation Test}

The biodegradation test was carried out following the procedure reported by Zain et al.18, with small alterations. Films were cut to $2.5 \times 2.5 \mathrm{~cm}$ size and then weighed. A 20 -cm-thick plastic container was prepared and supplied with compost media. The film was then buried in the media to a depth of up to 10 $\mathrm{cm}$. After $5,10,15$, and 20 days, the films were withdrawn from the media, soaked in $70 \%$ ethanol, and dried in a $50^{\circ} \mathrm{C}$ oven for $24 \mathrm{~h}$.

\section{Statistical Analysis}

SPSS software was used for statistical analysis. The data were represented as the average standard deviation of three repetitions for each sample and evaluated using one-way ANOVA at p-value $<0.05$. Duncan's multiple ranges at $\mathrm{p}$-value $<0.05$ were being used to verify significant difference analysis.

\section{Fourier Transform Infrared (FTIR) Spectroscopy}

\section{RESULTS AND DISCUSSION}

FTIR spectra were used to determine the intermolecular interaction pattern between a mixture of chitosan and cellulose, as well as plasticizers derived from castor oil. Figure-1 depicts the FTIR spectra of the films.

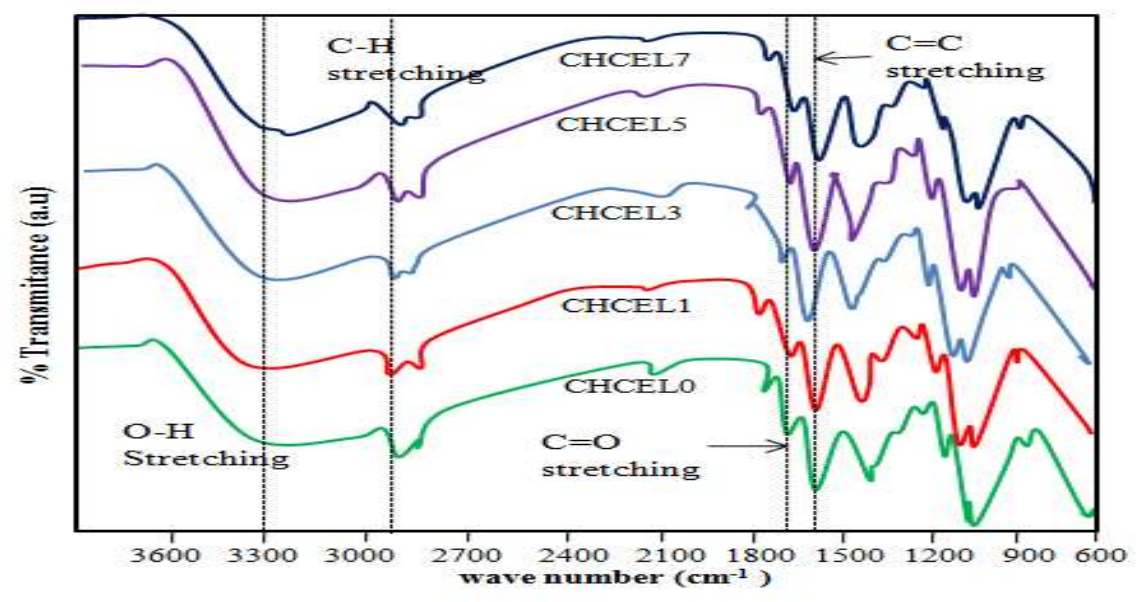

Fig.-1: FTIR Spectra of Chitosan/Cellulose Films 
In general, the absorption peaks in the FTIR spectra of CHCEL blended films are identical. All films showed distinctive absorption peaks at $1642,1551,1405$, and $1021 \mathrm{~cm}^{-1}$, corresponding to $\mathrm{C}=\mathrm{O}$ stretching, N-H bending, C-N stretching, and C-O-C stretching vibrations. ${ }^{16}$ The stretching vibration of the CHCEL of free hydroxyl groups $(\mathrm{O}-\mathrm{H})$ and amino groups $(\mathrm{N}-\mathrm{H})$ is attributed to the peak at 3700 $3000 \mathrm{~cm}^{-1} \cdot{ }^{17}$ A peak at $2924 \mathrm{~cm}^{-1}$ was assigned to $\mathrm{C}-\mathrm{H}$ stretching vibration. The addition of cellulose at 3,5 , and $7 \%$ caused a shift in the vibrational wavenumber of the hydroxyl functional group from 3251.9 to $3262.8,3263.2$ and $3266.7 \mathrm{~cm}^{-1}$. This is due to the interaction between cellulose and chitosan through the formation of hydrogen bonds.

\section{Thickness and Water Uptake}

Table-2 presents data on film thickness and kinetic parameters. The film thickness was considerably different $(\mathrm{p}<0.05)$ between the cellulose-free sample and the cellulose-added sample. The addition of cellulose to the chitosan improves the film's thickness. The increased intermolecular space between polymer chains is most likely responsible for the increased thickness of the film. ${ }^{18}$ The presence of cellulose increased the availability of hydrophilic and hydrophobic groups in polymer molecules, leading to the growth of sponge-like structures. ${ }^{18}$

Table-2: Thickness and kinetic parameter of film samples

\begin{tabular}{c|c|c|c|c|c}
\hline \multirow{2}{*}{ Film samples } & \multicolumn{3}{|c|}{ Kinetic Parameters } & \multicolumn{2}{c}{ Roughness Parameters } \\
\cline { 2 - 6 } & Thickness $(\mathrm{mm})$ & $\mathrm{D}\left(\times 10^{-4} \mathrm{~mm}^{2} / \mathrm{s}\right)$ & $\mathrm{M}_{\curvearrowleft}(\%)$ & $\mathrm{Ra}(\mathrm{nm})$ & $\mathrm{Rq}(\mathrm{nm})$ \\
\hline CHCEL0 & $0.24 \pm 0.006^{\mathrm{a}}$ & $13.40 \pm 8.29^{\mathrm{ab}}$ & $128.78 \pm 6.18^{\mathrm{d}}$ & 120 & 170 \\
\hline CHCEL1 & $0.33 \pm 0.015^{\mathrm{b}}$ & $10.09 \pm 1.29^{\mathrm{ab}}$ & $108.78 \pm 2.51^{\mathrm{c}}$ & 150 & 180 \\
\hline CHCEL3 & $0.33 \pm 0.006^{\mathrm{b}}$ & $8.37 \pm 2.02^{\mathrm{a}}$ & $104.58 \pm 10.94^{\mathrm{bc}}$ & 170 & 200 \\
\hline CHCEL5 & $0.35 \pm 0.012^{\mathrm{c}}$ & $20.53 \pm 7.30^{\mathrm{bc}}$ & $95.92 \pm 3.18^{\mathrm{ab}}$ & 220 & 280 \\
\hline CHCEL7 & $0.39 \pm 0.026^{\mathrm{d}}$ & $28.23 \pm 8.71^{\mathrm{c}}$ & $90.89 \pm 1.41^{\mathrm{a}}$ & 240 & 280 \\
\hline
\end{tabular}

Note: value within a column followed the same letter shows no significant difference at $\mathrm{p}<0.05$

All of the films absorbed water quite quickly, with all film samples reaching optimal absorption within one min. This is most likely affected by the amount of hydrophilic group generated by chitosan while hydrogen bonds with water. ${ }^{19}$ The differential in the chemical potential of water molecules attached to the film matrix is a major determinant of water absorption ${ }^{20}$. According to the $\mathrm{M}$ value data in Table-2, it was discovered that the $M$ value was significantly $(p<0.05)$ different for all CHCEL film samples. The maximum absorption capacity of the film reduces as the cellulose fraction of the film matrix increases.

\section{Atomic Force Microscopy (AFM)}

Figure- 2 shows AFM images, and Table-2 shows the surface roughness parameters $\mathrm{Ra}$ and $\mathrm{Rq}$ of all CHCEL blended films. It was discovered that all films have a rather rough surface. However, no trace of $\mathrm{CH}$ or $\mathrm{CEL}$ was detected, indicating that the blend of CEL and $\mathrm{CH}$ was completely compatible. The absence of fractures and aggregation on the film surface suggested that a good dispersion of the chitosancellulose mix in the CHCEL matrix had been achieved. This result was consistent with the findings of Hasan et al. ${ }^{3}$ Quantitatively, there was a strong correlation $(\mathrm{p}<0.05)$ between the addition of cellulose and the surface roughness of CHCEL films, with the higher the concentration of cellulose provided resulting in a rougher surface of the produced film. The smoothest surface was native chitosan film, which had the lowest $\mathrm{Ra}$ and $\mathrm{Rq}$ values of $120 \mathrm{~nm}$ and $140 \mathrm{~nm}$, respectively. While the film with the addition of 7\% w/w cellulose had the greatest $\mathrm{Ra}$ and $\mathrm{Rq}$ values of $240 \mathrm{~nm}$ and $280 \mathrm{~nm}$, respectively. This result was most likely caused by an increase in intermolecular space between polymer chains, which was corroborated by thickness data. However, the surface of the film produced by this research was smoother than that obtained by earlier studies combining sugar palm starch and chitosan. ${ }^{6}$

\section{Mechanical Properties}

Stress-strain curves, tensile strength, and elongation will be used to explain the mechanical properties of CHCEL film samples. All sample CHCEL films' stress-strain curves, tensile strength, and elongation at break were depicted in Fig.-3. The chitosan film without the addition of cellulose has the lowest tensile 
RASĀYAN J. Chem.

Vol. 14 | No. 3 |2147-2153| July - September | 2021

strength, as seen in Fig.-3. The incorporation of cellulose greatly strengthened the sample's strength; samples with 7\% w/w cellulose have the greatest TS and EB values, namely $56.21 \mathrm{MPa}$ and $16.14 \%$, respectively. This is most likely due to chitosan and cellulose's strong interaction via hydrogen bonds between the polymer molecular chains. ${ }^{17,21}$ As required, a film used for packaging must have a TS of at least 3.5 $\mathrm{Mpa}^{22}$ As a result, all of the films obtained met the TS requirements for food packaging.

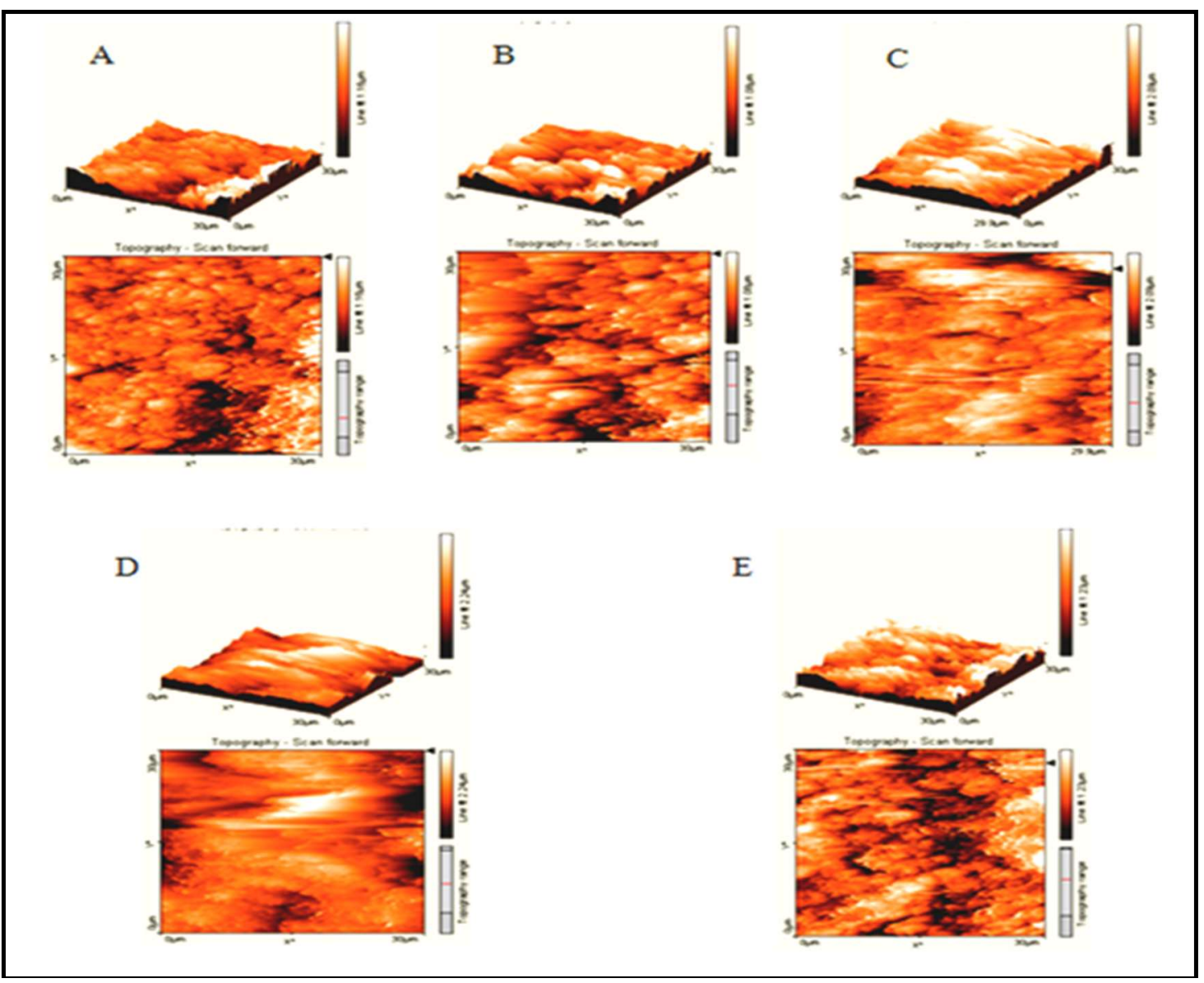

Fig.-2: AFM Image; (A) CHCEL0; (B) CHCEL1; (C) CHCEL3; (D) CHCEL5; (E) CHCEL7

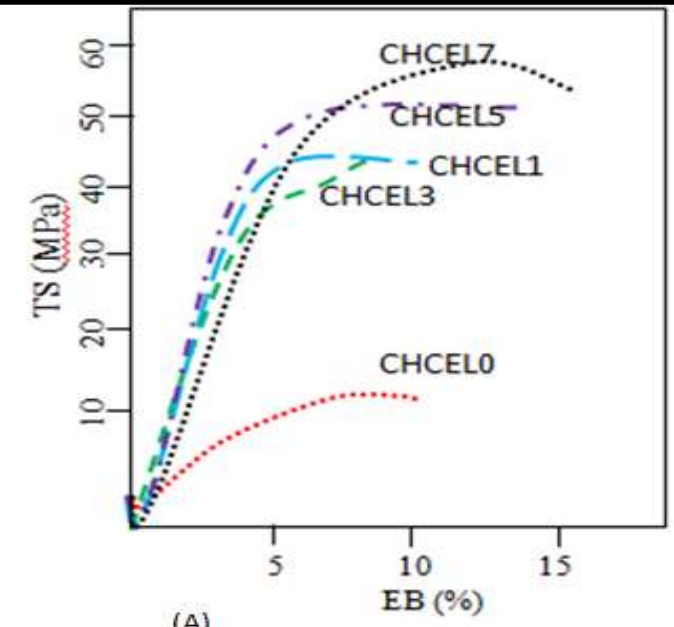

(A)

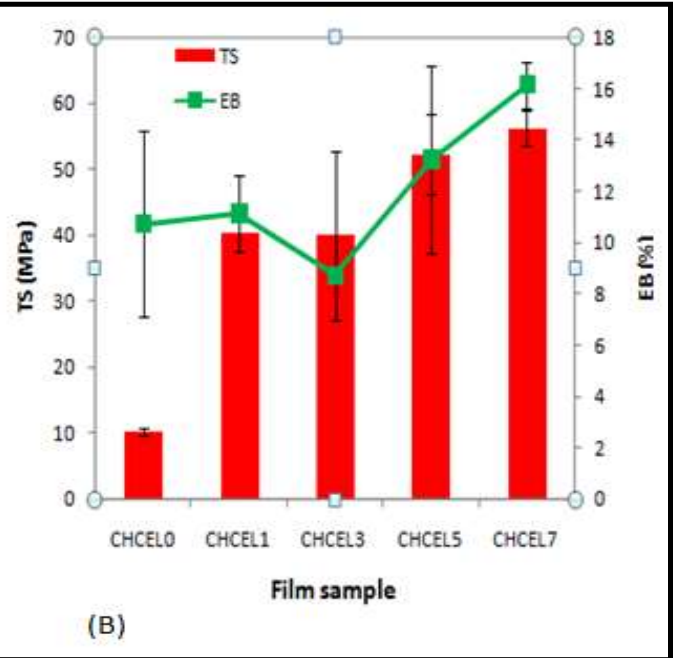

Fig.-3: Mechanical Properties; (A) Stress-strain Curve; (B) TS and EB Value of CHCEL 
RASĀYAN J. Chem.

Vol. 14 | No. 3 |2147-2153| July - September | 2021

\section{Biodegradation Test}

The biodegradation test was performed to examine the potential of bioplastic sheets to deteriorate spontaneously in the environment. The physical appearance of each sample exposed to biodegradability testing for 5, 10, and 15 days is depicted in Figure-4. Rapid degradation was seen over 5 days, with the degradation and color change trends indicating biological action on the samples. After 5 days, all samples had cracked into crumbles. The CHCEL5 and CHCEL7 samples were entirely biodegradable after 10 days, with no evidence of cracking. After 15 days, all samples were entirely biodegradable and had no crumbs. These findings suggested that the cellulose content has a major influence on the biodegradability of film, with the higher the cellulose content, the faster the film biodegrades. These biodegradation results are consistent with recent findings in the literature. ${ }^{6}$

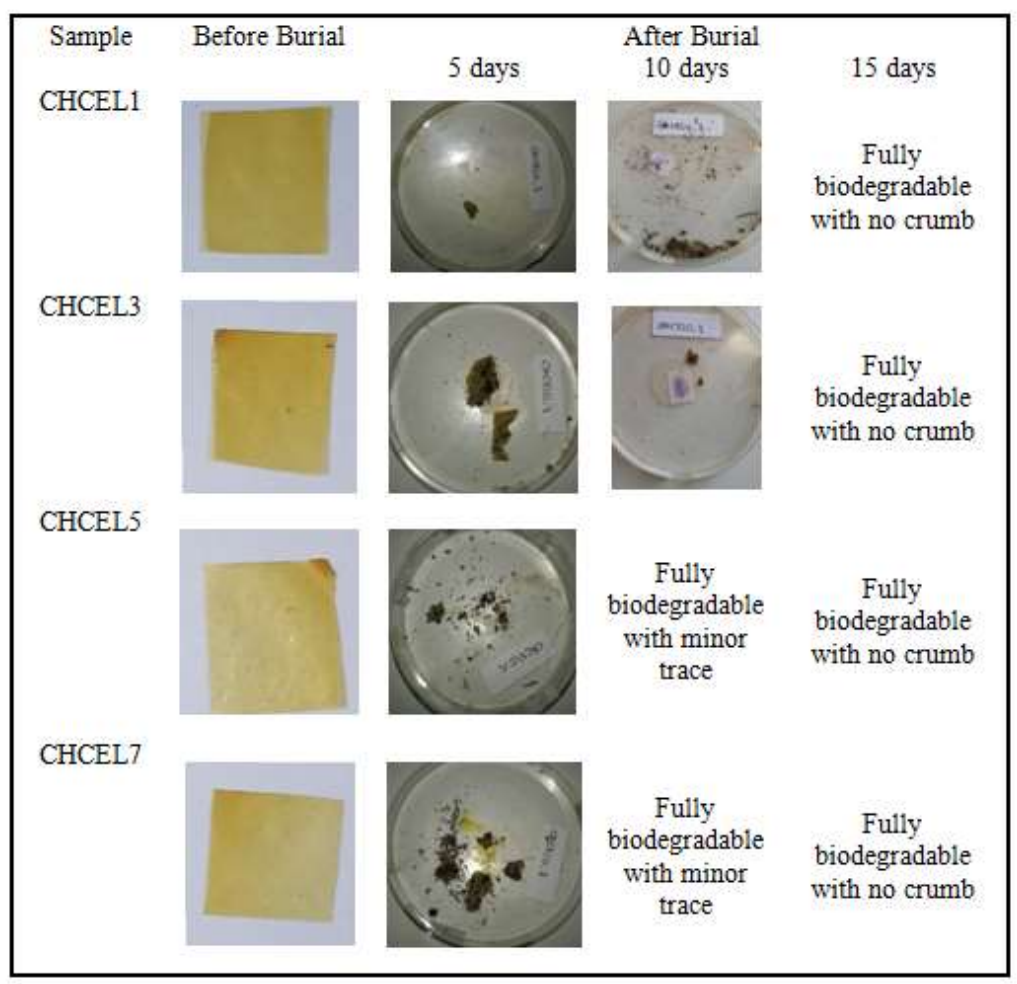

Fig.-4: Biodegradable Films before and after burial in Compost Media

\section{CONCLUSION}

Straw waste cellulose-chitosan composite films have been successfully produced. The addition of cellulose to the chitosan matrix improved mechanical strength while decreased water absorption. After 15 days of burial, the film is entirely biodegradable with no crumbs. Based on the findings of this study, CHCEL mix films generated through this research have a high potential for usage as sustainable food packaging films.

\section{REFERENCES}

1. I.M. Arcana, B. Bundjali, M. Hasan, M.A. Zulfikar, and K. Hariyawati, Polymer International, 60(10), 1535(2011), https://doi.org/10.1002/pi.3114

2. I.M. Arcana, B. Bundjali, M. Hasan, K. Hariyawati, H. Mariani, S.D. Anggraini, A. Ardana, Journal of Polymers and the Environment, 18(3), 188(2010), https://doi.org/10.1007/s10924-010-0189-9

3. E. Zaidar, S. Lenny, S.A. Amaturrahim, S.A. Situmorang, J.N. Sari, S.U. Rahayu, and S. Gea, Rasayan Journal of Chemistry, 14(2), 1281(2021), http://dx.doi.org/10.31788/RJC.2021.1425929

4. M. Hasan, R. Rusman, I. Khaldun, L. Ardana, M. Mudatsir, and H. Fansuri, International Journal of Biological Macromolecules, 163, 766(2020), https://doi.org/10.1016/j.ijbiomac.2020.07.076

5. M. Hasan, R.F.I. Rahmayani, Munandar, Journal of Physics: Conference Series, 333, 012087 (2018), https://doi.org/10.1088/1757-899X/333/1/012087 
RASĀYAN J. Chem.

Vol. 14 | No. 3 |2147-2153| July - September | 2021

6. M. Hasan, D.A. Gopakumar, N.G. Olaiya, F. Zarlaida, A. Alfian, C. Aprinasari, T. Alfatah, S. Rizal, and H.P.S.A. Khalil, International Journal of Biological Macromolecules, 156, 896(2020). https://doi.org/10.1016/j.ijbiomac.2020.04.039

7. S. Volpe, S. Cavella, P. Masi, and E. Torrieri, Food Packaging and Shelf Life, 13, 76(2017), https://doi.org/10.1016/j.fpsl.2017.07.002

8. P.S. Bakshia, D. Selvakumara, K. Kadirvelub, and N.S. Kumara, International Journal of Biological Macromolecules, 150, 1072(2019), https://doi.org/10.1016/j.ijbiomac.2019.10.113

9. M. Hasan, T.K. Lai, D.A. Gopakumar, M. Jawaid, F.A.T. Owolabi, E.M. Mistar, T. Alfatah, N.Z. Noriman, M.K.M. Haafiz, H.P.S. Abdul Khalil, Journal of Polymers and the Environment,27(7), 1602(2019), https://doi.org/10.1007/s10924-019-01457-4

10. S.W. Saragih, R. Hardiyanti, and I.P. Mahendra, Rasayan Journal of Chemistry, 14(1), 578(2021), http://dx.doi.org/10.31788/RJC.2021.1415883

11. M. Hasan, Zulfadli, M. Nazar, R.F.I. Rahmayani, G. Fajri, and H. Fansuri, Rasayan Journal of Chemistry, 12(3), 1390(2019), https://doi.org/10.31788/RJC.2019.1235326

12. H.P.S.A. Khalil, S.W. Yap, F.A.T. Owolabi, M.K.M. Haafiz, M.R. Fazita, D.A. Gopakumar, M. Hasan, and S. Rizal, Journal of Physical Science, 30, 23(2019), https://doi.org/10.21315/jps2019.30.s1.2

13. A.G. Siti Waqina, A.B. Aznizam, and S. Sani Amril, Journal of Plastic Film and Sheeting, 32(2), 140 (2016), https://doi.org/10.1177/8756087915590189

14. F.M. Pelissari, M.M. Andrade-Mahecha, P.J. do A. Sobral, and F.C. Menegalli, Journal of Colloid and Interface Science,505, 154(2017), https://doi.org/10.1016/j.jcis.2017.05.106

15. A.H.M. Zain, M.K. Ab Wahab, and H. Ismail, Journal of Polymers and the Environment,26(2), 691(2018), https://doi.org/10.1007/s10924-017-0978-5

16. M. Hasan, E.W.N. Chong, S. Jafarzadeh, M.T. Paridah, D.A. Gopakumar, H.A. Tajarudin, S. Thomas, and H.P.S.A. Khalil, Polymers.11(2), 210(2019), https://doi.org/10.3390/polym11020210

17. M. Hasan, D.A. Gopakumar, V. Arumughan, Y.B. Pottathara, K.S. Sisanth, D. Pasquini, M. Bračič, B. Seantier, A. Nzihou, S. Thomas, S. Rizal, and H.P.S. Abdul Khalil, Polymers, 11(3), 495(2019), https://doi.org/10.3390/polym11030495

18. J.M. Frick Pavoni, C.L. Luchese, and I.C. Tessaro, International Journal of Biological Macromolecules, 138, 693(2019), https://doi.org/10.1016/j.ijbiomac.2019.07.089

19. I. Surya, N.G. Olaiya, S. Rizal, I. Zein, N.A.S. Aprilia, M. Hasan, E.B. Yahya, K.K. Sadasivuni, and H.P.S.A. Khalil, Polymers, 12(1), 115(2020), https://doi.org/10.3390/polym12010115

20. S. Sousa, A. Costa, A. Silva, and R. Simões, Polymers, 11(1), 66(2019), https://doi.org/10.3390/polym11010066

21. M. Hasan, T.K. Lai, E.W.N. Chong, D.A. Gopakumar, S. Rizal, M.S. Hossain, M.R.N. Fazita, M.K.M. Haafiz, M.T. Paridah, and H.P.S. Abdul Khalil, BioResources, 14(4), 9198(2019), https://doi.org/10.15376/biores.14.4.9198-9213

22. M.F. Di Filippo, L.S. Dolci, L. Liccardo, A. Bigi, F. Bonvicini, G.A. Gentilomi, N. Passerini, S. Panzavolta, and B. Albertini, Food Hydrocolloid, 111, 106247(2021), https://doi.org/10.1016/j.foodhyd.2020.106247

[RJC-6377/2021] 